\title{
Odontogenic Infection. Review of the Pathogenesis, Diagnosis, Complications and Treatment
}

\author{
Roberto Ortiz ${ }^{1 *}$ and Vanessa Espinoza ${ }^{2}$ \\ ${ }^{1}$ General Dentist, Private Practice, Guayaquil, Ecuador
}

${ }^{2}$ Chief, Oral and Maxillofacial Surgery Department, Hospital General Guasmo Sur, and Private Practice, Guayaquil, Ecuador

*Corresponding author: Dr. Roberto Ortiz, General Dentist, Private Practice, Los Ceibos, Guayaquil, Ecuador, Tel: +59399-749-0300

\begin{abstract}
Odontogenic infections are frequently seen in the dental practice, being dental caries its main etiology; therefore, dentists should be familiarized with its presentation and management as it can spread rapidly and have serious consequences. The purpose of this article is to provide essential knowledge on the pathogenesis, diagnosis, possible complications and treatment of odontogenic infections.
\end{abstract}

\section{Keywords}

Odontogenic infections, Dental infection, Odontogenic infection complications, Odontogenic infection management

\section{Abbreviations}

OI: Odontogenic Infection; ID: Incision and Drainage; CT: Computed Tomography; MRI: Magnetic Resonance Imaging

\section{Introduction}

Odontogenic infection (OI) is defined as those infections that originate from pulpal or periodontal pathology that affect the alveolar bone and can spread through the bone marrow, cortical bone and periosteum to structures distant from the oral cavity [1].

$\mathrm{Ol}$ is one of the most common diseases, accounting for $60 \%$ of reason for dental consultation with the dentist [1,2]. The main etiology is dental caries, but it can also develop from pericoronitis, periodontal pockets or exodontia [3]. The severity of the infection depends on multiple factors, such as the virulence of the bacteria, the systemic state of the patient and the anatomical spaces affected.
Ocassionally, symptoms and clinical manifestations may become severe, requiring in-hospital management. Dissemination of Ol can compromise the airway, putting life at risk [4].

The principle of treatment dates back to the time of Hippocrates when it was established that the elimination of the infectious agent along with incision and drainage (ID) are key to the resolution of an OI [5]. In addition, it has to be accompanied by antibiotic therapy [6].

The purpose of this article is to provide essential knowledge on the pathogenesis, diagnosis, possible complications and management of odontogenic infections allowing the establishment of a treatment that contains the infection localized, avoiding its dissemination towards deep anatomical spaces; thus, ensuring the patient's safety.

\section{Pathogenesis}

\section{Host response to infection}

Immune response is mediated by the immune system, which is a complex of specialized cells that function as a protective barrier and is composed of an innate system and an acquired system [7].

The innate system is a non-specific defense mechanism that activates upon contact with an antigen. The acquired system, on the other hand, is an antigenspecific defense mechanism which has the capacity to recognize the antigen that is facing. Thus, creating memory cells that identify and act quickly against an

Citation: Ortiz R, Espinoza V (2021) Odontogenic Infection. Review of the Pathogenesis, Diagnosis, Complications and Treatment. Res Rep Oral Maxillofac Surg 5:055. doi.org/10.23937/26433907/1710055

Accepted: August 10, 2020; Published: August 12, 2021

Copyright: (c) 2021 Roberto OB, et al. This is an open-access article distributed under the terms of the Creative Commons Attribution License, which permits unrestricted use, distribution, and reproduction in any medium, provided the original author and source are credited. 
antigen in case of new exposure [7]. The cells that comprise the immune system are leukocytes consisting of $T, B$ and killer lymphocytes, granulocytes such as neutrophils, basophils, eosinophils and mast cells, and antigen-presenting cells such as macrophages, Langerhans cells and dendritic cells [8].

Bacterial invasion induces a series of immunological events to fight infection. The first defense cell of the organism is the macrophage, which fulfills a dual function by releasing chemotactic factors that attract neutrophils to the site of the lesion and as an antigen-presenting cell to the neutrophils, responsible for bacterial phagocytosis. The release of chemical mediators such as histamines, bradykinins, cytokines and prostaglandins, causes vasodilatation and opening of spaces between endothelial cells allowing the extravasation of plasma into the interstitial spaces where it accumulates, followed by the formation of fibrin. During an infectious process the classic signs of inflammation such as swelling, erythema, pain, edema and loss of function are observed [9]. This process is summarized as: 1) Hyperemia due to vasodilatation; 2) Plasma and leukocyte extravasation; 3) Increased permeability and neutrophil diapedesis; 4) Fibrin wall formation; 5) Bacterial phagocytosis; 6) Deposition of necrotic material by macrophages [2].

\section{Immunocompromised patient}

There are multiple conditions that lead to a depression of the immune system such as long-term use of corticosteroids, transplants, HIV, alcoholism, liver disease, diabetes, among others [10].

The presence of immunosuppressive medical conditions is very important in the development of OI. Systemic diseases, even more than the location of infection, have been shown to influence in longer hospitalization and recovery time [11].

The most common systemic condition is diabetes, which when uncontrolled, increases the severity of infection and hospital stay due to decreased immune system function [12].
In uncontrolled diabetes hyperglycemia occurs, affecting the defense cells, favoring the persistence of an infectious process due to the following factors $[7,13,14]$ :

1. Decreased chemotaxis, adhesion, migration and phagocytosis of leukocytes. They present less defensive capacity against bacteria and prolong the inflammatory state.

2. Decreased proliferation of fibroblasts, endothelial cells and collagen. Impairs tissue repair.

3. Macrophages and monocytes evade apoptosis, thus increasing cytokine production and prolonging the inflammatory process. Chronic inflammation increases insulin resistance.

4. Microangiopathy decreases blood flow and consequently decreases oxygen and nutrients to defensive and reparative cells. Also, it hinders the arrival of antibiotics to the site of infection.

5. Decreased proliferative capacity of keratinocytes which delays re-epithelialization of wounds.

\section{Microbiology}

The normal oral flora is mixed, composed of aerobic/ facultative anaerobic and strict anaerobic bacteria [15]. Aerobic bacteria have the ability to survive and grow in an oxygenated environment. They prepare the environment for the proliferation and invasion of anaerobic bacteria which survive and develop in a hypoxic environment. Strict anaerobic bacteria are responsable for greater invasion and destruction of tissues due to their high virulence [4].

OI is polymicrobial with a higher prevalence of gram-positive cocci and gram-negative rod, being the streptococci the most prevalent Table $1[16,17]$. There is a 3:1 ratio of anaerobic to aerobic bacteria. Anaerobic bacteria are found in $75 \%$ while aerobic bacteria are found in $25 \%$ [2]. Although the virulence of the bacteria is a feature that can determine the severity of the infection, on many occasions the bacterial load will be

Table 1: Frequent bacterias in odontogenic infections. Adapted from Brook I, et al. [17].

\begin{tabular}{|c|c|c|c|}
\hline Gram stain & Type of bacteria & Aerobes or facultative anaerobes & Strict anaerobios \\
\hline \multirow{2}{*}{ Gram-positive } & Cocci & $\begin{array}{l}\text { Streptococcus spp } \\
\text { Staphylococcus spp }\end{array}$ & $\begin{array}{l}\text { Peptococcus spp } \\
\text { Peptostreptoccus spp }\end{array}$ \\
\hline & Rods & Lactobacillus spp & $\begin{array}{l}\text { Eubacterium } \\
\text { Actinomyces }\end{array}$ \\
\hline \multirow[b]{2}{*}{ Gram-negative } & Cocci & & Veilonella \\
\hline & Rods & $\begin{array}{l}\text { Capnocytophaga spp } \\
\text { Actinobacilo spp } \\
\text { Eikenella spp }\end{array}$ & $\begin{array}{l}\text { Porphyromonas spp } \\
\text { Bacteroides spp } \\
\text { Prevotella spp } \\
\text { Fusobacterium spp } \\
\text { Selenomonas sputigena }\end{array}$ \\
\hline
\end{tabular}


Table 2: Anatomic spaces of the oral and maxillofacial region. Adapted from Hupp JR, et al. [20].

\begin{tabular}{|l|l|l|}
\hline \multirow{2}{*}{ Primary } & Localization & Spaces \\
\hline \multirow{2}{*}{ Secondary } & Maxillary & Buccal, palatal, vestibular \\
\hline & Mandibule & Vestibular \\
\hline Maxillary & $\begin{array}{l}\text { Canine/infraorbital, orbital } \\
\text { Advanced }\end{array}$ & $\begin{array}{l}\text { Sublingual, submandibular, parotid, pterigomandibular, superficial temporal, } \\
\text { submental, deep temporal, peritonsillar masseteric }\end{array}$ \\
\hline Mandibule & Lateral pharyngeal, retro pharyngeal, carotid, pretracheal, visceral, mediastinum \\
\hline
\end{tabular}

Table 3: Severity scale of the compromised anatomic spaces. Adapted from Flynn T, et al. [21].

\begin{tabular}{|l|l|}
\hline Severity Scale & Anatomic space \\
\hline 1: Mild risk & Canine, vestibular maxillary and mandibular, palatal \\
\hline 2: Moderate risk & Submandibular, sublingual, submental, pterigomandibular, submasseteric, temporal, \\
\hline 3: Severe risk & Retropharyngeal, pterigopalatal, pretracheal, pterigopharyngeal \\
\hline 4: Extreme risk & Mediastinum, intracranial, prevertebral \\
\hline
\end{tabular}

more important in overcoming the host defense system [4]. The increment in bacterial load increases the diversity of microorganisms. When interacting among them there is a synergism that increases their virulence [18].

\section{Dissemination of odontogenic infection}

Ol initiate in dental and/or periodontal tissues which they spread through to deep anatomical structures [19]. When bacteria reaches the dental pulp, it causes necrosis and induces the formation of an abscess. Once the infection is established in the periapical tissue, it crosses cortical bone periosteum and goes through the path of least resistance determined by [20]:

1. Muscle attachments that mark the direction and location of infection.

2. Position of the dental apex.

3. Thickness of the bone surrounding the tooth.

The dissemination of $\mathrm{Ol}$ occurs by three routes: 1) By continuity through anatomical spaces which, by being virtual spaces and not having real physical limits, facilitate the spread of the infection between them Table 2. 2) By hematic route when entering the circulatory system. 3) By lymphatic route when entering the lymphatic system of the head and neck it can spread through the lymph from the primary nodule, close to the infectious focus, to a secondary nodule in a distant site [4].

Flynn, et al. classify the severity of infection according to the anatomical spaces invaded [21] Table 3. It has been reported that the most frequently involved aponeurotic space is the vestibular space (50\%) [1]; while other studies concluded it was the buccal space (60\%) [4] and the submandibular space (35\%) [22]. Beyond these differences, it was concluded that odontogenic infections are responsible for $43 \%-60 \%$ of deep neck space infections $[23,24]$.

\section{Diagnosis}

\section{Clinical presentation}

The diagnosis of an $\mathrm{Ol}$ is made from the patient's clinical history and symptoms. Establishing the onset of symptoms and propagation speed of the infection clarifies the severity [20].

Physical examination of the patient plays an important role during diagnosis. In advanced stages of $\mathrm{Ol}$ an alteration of vital signs along with leukopenia are manifested as a Systemic Inflammatory Response Syndrome. Temperature is $\left\langle 36^{\circ}\right.$ or $>38^{\circ}$, heart rate $>$ $90 / \mathrm{min}$, respiratory rate $>20 / \mathrm{min}$, and neutrophils $>$ $12,000 \mathrm{~mm}^{3}[25]$.

During the examination, swelling with redness of the affected area are observed Figure 1. The dental, periodontal and perioral status of the patient should be assess [9]. Three stages can be determined during the examination of the patient with OI: Inoculation, cellulitis or abscess [20] Table 4.

The classic signs and symptoms of inflammation are evidenced: pain, redness, heat, edema and loss of function. Depending on the severity of the infection thermal elevation, diaphoresis, general malaise, odynophagia, dyspnea, dysphagia and trismus are present; some of these signs and symptoms are indicators of an infection that requires in-hospital management by a specialist $[3,9,20]$.

\section{Imaging}

There is a wide variety of options such as panoramic radiography, computed tomography (CT), magnetic resonance imaging (MRI) and ultrasound $[16,26]$.

Panoramic radiography is the imaging study of first choice in the protocol for the Ol management since it shows signs of bone and dental destruction that guides the clinician to the origin of the infection [27] Figure 2. 
Table 4: Stages of infection. Adapted from Hupp JR, et al. [20].

\section{Stages of infection}

\begin{tabular}{|c|c|c|c|}
\hline & Edema & Cellulitis & Abscess \\
\hline Definition & $\begin{array}{l}\text { Interstitial fluid from neighboring } \\
\text { inflammation or infection }\end{array}$ & $\begin{array}{l}\text { Spread of bacteria into } \\
\text { space along with interstitial } \\
\text { accumulation }\end{array}$ & $\begin{array}{l}\text { Breakdown of liquefactive } \\
\text { necrosis to form purulence } \\
\text { within the soft tissue }\end{array}$ \\
\hline Duration & $0-3$ days & 3-7 days & $>5$ days \\
\hline Pain & Mild-moderate & Severe & Severe \\
\hline Location & Diffuse & Diffuse & Well-circumscribed \\
\hline Palpation & Soft & Tender & Fluctuant \\
\hline Skin & Normal to firm & Firm & Firm to hard \\
\hline Loss of function & None to minimal & Moderate to severe & Moderate to severe \\
\hline Tissue fluid & Edema & Serosanguineous or purulence & Collection of purulence \\
\hline Severity & Mild & Moderate to severe & Severe \\
\hline Bacteria profile & Aerobic & Mixed & Anaerobic \\
\hline
\end{tabular}
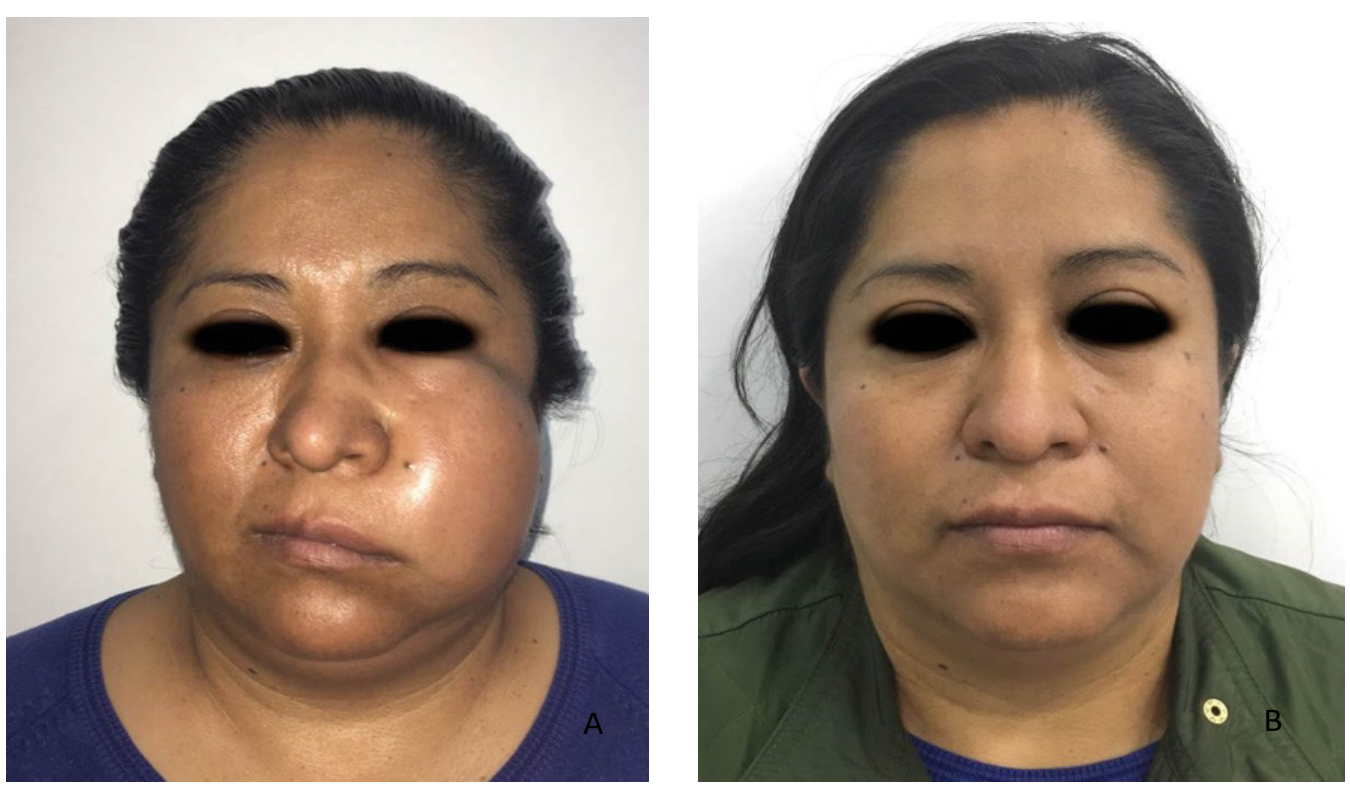

Figure 1: A) Swelling of the buccal space, Loss of nasolabial fold; B) Remission of infection.

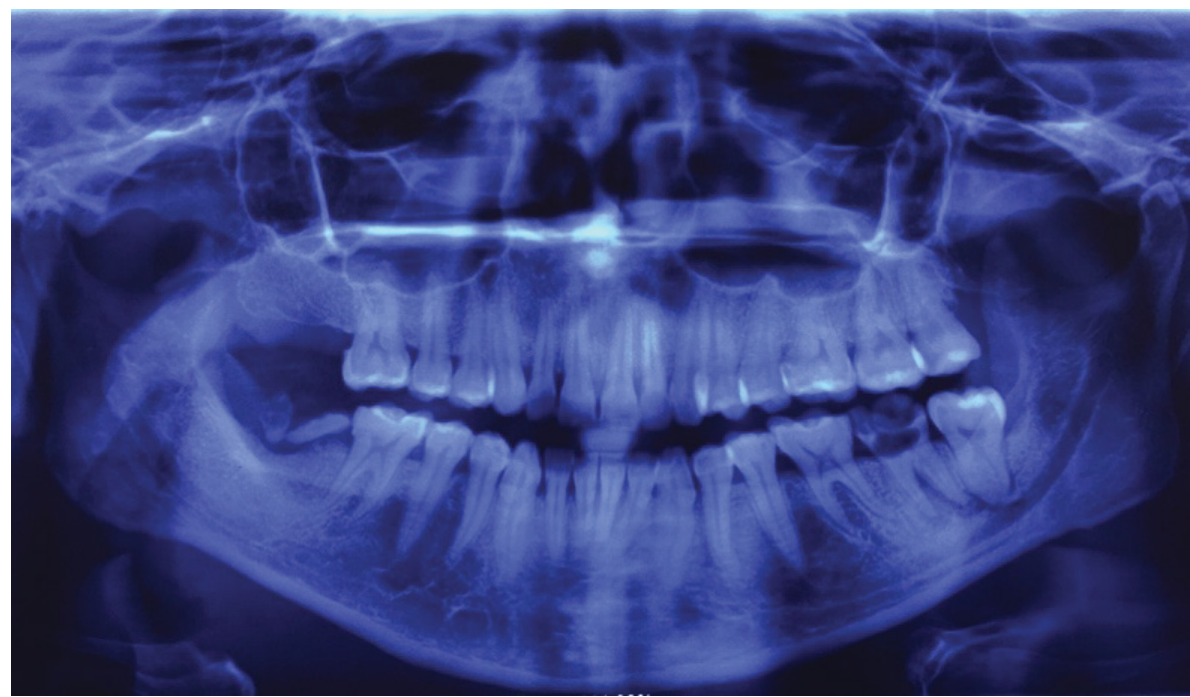

Figure 2: Panoramic X-ray, Periapical osseous destruction of the second left lower molar. Roots remains of the second right lower molar. 


\section{Adult presenting with pain and/or swelling in the head and neck}

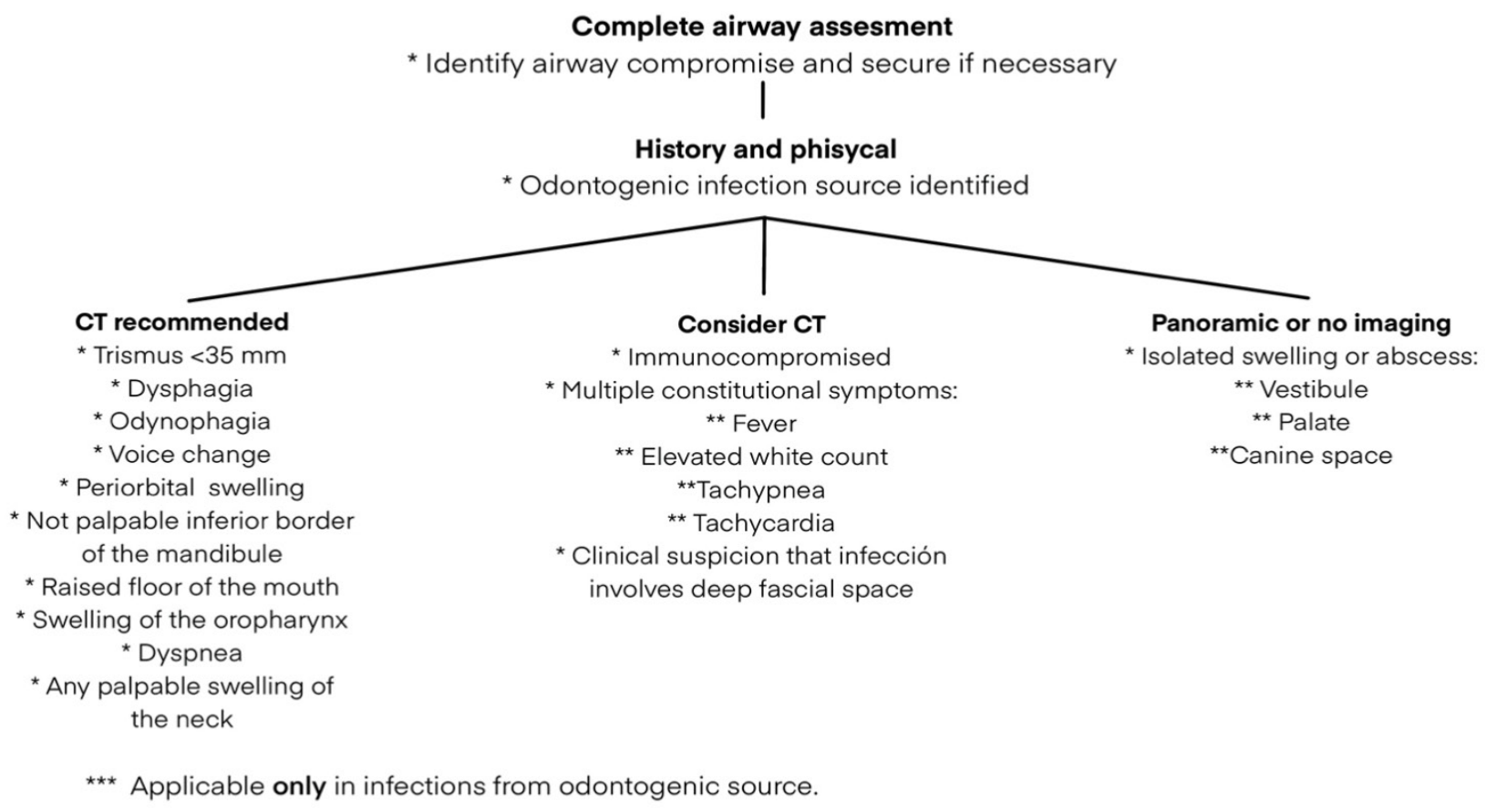

Figure 3: Image ordering guidelines for odontogenic infection. Adapted from Weyh AM, et al. [28].

The overuse of CT as diagnostic imaging in cases of Ol has been discussed on several occasions. Weyh, et al. published a guideline for $\mathrm{CT}$ request that considers signs and symptoms as "red flags" that suggest an increased risk of dissemination of the infection to deep anatomic spaces increasing the risk of complications [28] Figure 3. Some of them are trismus, dyspnea, dysphagia, non-palpable lower jaw border, tachycardia, among others [28,29].

The use of MRI, despite being superior in the diagnosis of bone and soft tissue alterations, has great disadvantages such as the time and money needed to perform it. On the other hand, the ultrasound can be a great tool in cases where a CT scanner is not available, allowing the evaluation and differentiation of purulent collections and vascularized areas [16].

\section{Laboratory studies}

Laboratory studies are not usually solicited during the treatment of an odontogenic infection. However, they can be useful when the infection occupies deep spaces that complicate the clinical examination. The study to request is a complete blood count; in which the white cells are evaluated with greater emphasis on the differential count. During the development of the bacterial infection, neutrophils are elevated above $12,000 \mathrm{~mm}^{3}$ as a sign that the immune system is fighting the infection; while after treatment, as a sign of resolution of the infection, neutrophils return to normal levels [19].

\section{Culture}

Regularly the elimination of the infectious focus, incision and drainage, and empirical pharmacological treatment are sufficient for the remission of the infection. Most are localized and can be treated on the outpatient basis; therefore, culture is not justified $[28,30]$.

Culture and bacterial sensitivity testing are ordered when infections progress rapidly to spaces of moderate or severe risk, recurrent infections, immunocompromised patients, infections that don't improve after 48 hours of antibiotic therapy $[20,30]$.

The technique of sample collection for culture and antibiogram is of great importance. Contamination of the sample by bacteria belonging to the normal flora of the skin or oral cavity should be avoided at all times, so the area should be previously sterilized [4].

The best method for taking a sample is by aspiration of at least $2 \mathrm{ml}$ of purulent content. However, if incision and drainage are required, "culturettes" tubes, which are sterile tubes containing conveyance for aerobic and anaerobic bacteria, should be prepared [20].

\section{Complications}

In normal systemic circumstances the immune system manages to contain the dissemination of the infection, so the vast majority of Ol are localized. Patients with systemic diseases in which their defense mechanisms are affected, present a greater risk of developing complications, which can be local, by establishing themselves in adjacent tissues of the face and neck, or systemic, by spreading towards the circulation causing septicemia or infection distant from its source [22]. Due to the proximity of structures such as the airway, brain 


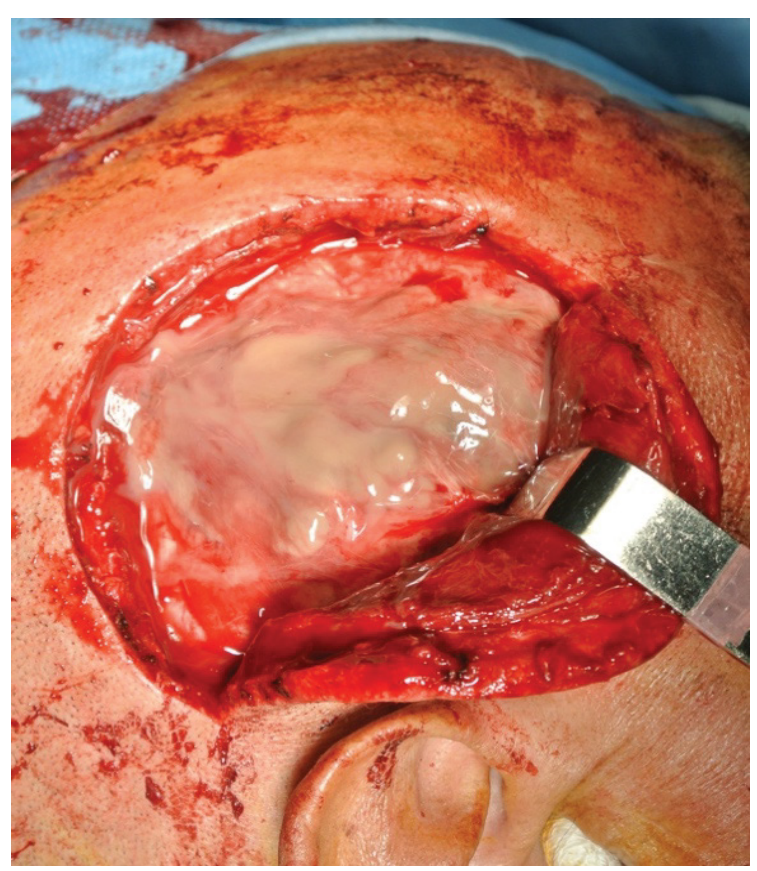

Figure 4: Abscess of the temporal space.

and heart, early diagnosis and treatment should be carried out to prevent danger to the patient's life. The OI has a mortality rate of $10-40 \%$ [25].

Multiple complications have been reported as a consequence of odontogenic infection such as: Necrotizing mediastinitis [31], Ludwig's angina [32], infratemporal and temporoparietal fossa abscesses [33] Figure 4, deep neck infections [23,24], meningitis [34], osteomyelitis [35], intracranial abscesses [36,37], cavernous sinus thrombosis [38], necrotizing fasciitis [25], airway obstruction [25], and death [31,39].

\section{Ludwig's angina}

Is the most common complication of OI [2]. It refers to a diffuse cellulitis that occupies the submental, submandibular and sublingual space bilaterally. Is considered as an emergency because of its rapid onset [6]. Ludwig's angina from odontogenic source, usually, originates from second and/or third lower molar due to the proximity of the dental apices with the submandibular and sublingual spaces which communicate intimately with the submental space, and can spread to pharyngeal spaces until reaching the mediastinum [40].

Some classic signs of Ludwig's angina are lingual proptosis and elevation of the floor of the mouth which obstructs the airway causing dyspnea, dysphagia, dysphonia and cyanosis [4].

Treatment consists primarily on securing the airway either by endotracheal intubation or tracheostomy [6]. Elimination of the source of infection, incision and drainage of all infected spaces, and antibiotic therapy [41].

\section{Osteomyelitis}

Osteomyelitis is a rare infection and inflammation of the medullary zone of the bone due to bacterial invasion originating from different factors such as mandibular trauma, odontogenic or non-odontogenic infections that spread by blood. The extensive bone destruction that is usually seen implies risk of fracture of the affected bone [35]. Is more frequent in the mandible since the blood vessels of the periosteum do not penetrate the cortical bone [20].

Among the characteristics of osteomyelitis are pain, tenderness, sinuous tracts, suppuration, bone sequestration. Radiographically, no signs of infection are observed during the first weeks. In chronic stages, bone sequestrum is observed as a radiolucent image that represents necrosis and bone destruction. A halo of greater density around the sequestrum, called involucrum, suggests bone regeneration as a response to inflammation [25]. The indicated treatment are broad-spectrum antibiotic therapy and profuse surgical curettage; also, bone resection for large bone destruction [2].

\section{Cavernous sinus thrombosis}

Is an infection that affects the cerebral sinuses. Because veins don't contain valves, blood flow arrives from several directions, connecting the cavernous sinus to the face through the angular vein which connects with the superior ophthalmic vein and to the palate through the pterygoid plexus via the inferior ophthalmic vein [25]. When infection reaches the cavernous sinus, regardless of the route, thrombosis occurs [9]. However, infections from the canine region via the angular vein are more frequent [38].

The cavernous sinus contains cranial nerves III, IV, VI, V1 and V2. Ophtalmoplegia, loss of infraorbital and supraorbital sensitivity, mydriasis, palpebral ptosis and amaurosis can be observed [38].

Surgery and intravenous broad-spectrum antibiotics are indicated. If treatment has not been initiated within the first 4 to 7 days, death usually occurs $[25,38]$. Along the years the mortality rate has decreased to less than $30 \%$ [38].

\section{Orbital abscesses}

Orbital abscesses are classified according to their location as pre-septal or post-septal. Post-septal abscesses, due to their proximity to the brain, have the potential to evolve into severe complications [41]. Its clinical characteristics are periorbital edema, chemosis, proptosis, ophthalmoplegia and loss of visual acuity [42].

\section{Deep neck infections}

Occurs when the infection spreads through anatomical 
planes to posterior regions of the neck such as the lateral pharyngeal and retropharyngeal spaces [23].

Deep neck infections from odontogenic source account for $43 \%$ of cases [23] with amortality rate of 10 $40 \%$ [43]. The airway can be compromised manifesting as dyspnea, dysphagia and dysphonia [23]. Because signs may appear in late stages, CT is recommended to observe the extent and location of the infection [44]. Surgical drainage and intravenous antibiotics are indicated [23].

\section{Necrotizing fasciitis}

Is an infection of the skin and subcutaneous tissue characterized by extensive and rapid dissemination associated to a mortality rate of $20-40 \%$. Aggressive and extensive surgical debridement, fasciotomy and ventilatory and circulatory support are mandatory [25].

\section{Cervicofacial actinomycosis}

An infection of the soft tissues of the maxillofacial region, but may involve osseous tissue [20]. Its etiologic agent is Actinomyces israelii, an anaerobic gram-positive rod. It can develop within days, weeks, months or years [45].

Clinically observed as a reddish-brown discoloration of the mandibular skin and sometimes as a suppurative irregular masses on the skin [45]. Unlike other infections, it does not spread through anatomic planes; rather, breaks through the soft tissues forming a sinuous tract that drains into the skin [20].

Diagnosis depends exclusively on culture results. As an anaerobic bacteria, maximum caution must be taken during sample collection, which should be by aspiration preferably [45].

Elimination of the infection source, extensive debridement, excision of the fistulous tract and placement of a drain are necessary for resolution of the infection [20]. It should be accompanied by antibiotics as penicillin $G$, penicillin $V$, erythromycin, cephalosporins or clindamycin [45].

\section{Airway obstruction}

When the airway is compromised, the use of accessory muscles such as the platysma and intercostal will be observed during respiration [46], stridor and sibilance will be heard, and to improve ventilation, the patient will present a head posture tilted forward or to the opposite side from the infection to align the upper airway with the trachea. Oxygenation less than $94 \%$ along with clinical signs of airway obstruction are indicative for establishing a safe airway by endotracheal intubation, tracheostomy or cricothyroidotomy [10]. The presence of trismus requires conscious intubation by fiberscope [47-49].

\section{Treatment}

The treatment of Ol depends on the stage of the disease and is composed of local management, antibiotic therapy and surgical management [19].

\section{Local management}

The initial treatment should consist of analgesics for pain control, glycemic balance in diabetic patients and control of temperature and electrolyte balance, since for each degree of fever there is a fluid loss of $250 \mathrm{ml}$ through perspiration $[10,19]$. The use of steroids is controversial, but some authors recommend the administration of a single dose of 2-3 mg/kg of methylprednisolone or 4-8 $\mathrm{mg}$ of dexamethasone over 24 hours to reduce swelling, pain and trismus $[6,16]$. In the authors experience it has been observed that warm physical means in the area of infection accelerates the formation of an abscess allowing early incision and drainage.

\section{Antibiotic therapy}

To choose the appropriate antibiotic, the stage of infection, causative microorganisms, route of administration, immunological status of the patient, and the spectrum and effect of action of the drug should be analyzed [2].

The spectrum of the antibiotic to be administered should be in accordance with the stage of infection, avoiding the excessive elimination of microorganisms of the normal flora that induces the overgrowth of resistant bacteria. During inoculation, there is only a gram-positive aerobic flora, so that reduced-spectrum antibiotics such as penicillin $\mathrm{V}$ can be administered. In cellulitis stage the flora is mixed and in abscess stage is strictly anaerobic with a greater prevalence of gram-negative bacilli. Wide-spectrum antibiotics such as amoxicillin/clavulanic acid, ampicillin/sulbactam, cephalosporins, azithromycin, clindamycin, moxifloxacin and metronidazole must be prescribed $[2,19]$. The length of treatment will depend on the clinician and the evolution of the infection; however, it is recommended between 2 and 7 days [46].

Selection between bactericidal and bacteriostatic antibiotic is of great importance. Bacteriostatic such as macrolides and tetracycline inhibit bacterial growth and multiplication, allowing the immune system cells to reach the site of infection and carry out phagocytosis. Bactericidal such as penicillin and clindamycin kill bacteria without relying on the immune system; therefore, are the antibiotics of choice in immunocompromised patients $[2,20]$.

If the infection progresses rapidly, there is no response to the first drug or increased coverage and bactericidal effect are required, the use of a double antibiotic regimen is indicated. Likewise, when the infection begins to spread from primary spaces, intravenous administration of antibiotics is ideal [2].

\section{Surgical management}




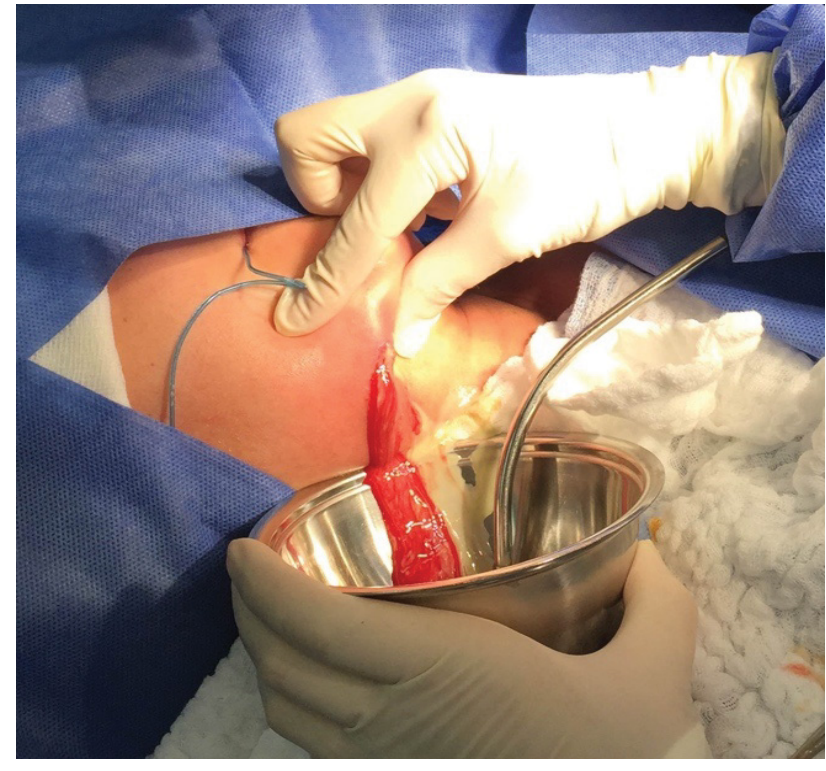

Figure 5: Incision and drainage of submandibular space.

Surgical management of $\mathrm{OI}$ is based on two principles, which are elimination of the infection source and incision and drainage [20].

Elimination of the primary source of infection can range from endodontic treatment to dental extraction. However, is recommended to wait for the antibiotic to take effect for a few days in cases of trismus or acute suppurative pericoronitis since the manipulation of tissues in this state may cause the infection to spread [10].

The purpose of ID is the debridement of necrotic tissue and elimination of bacteria found in underlying tissues. When an abscess is drained, the hydrostatic pressure of the area decreases, improving blood flow, thus increasing the supply of defense cells and antibiotic to the infected site [20] Figure 5.

The ideal time for an ID is a controversial topic. Some clinicians advise it should be performed during the cellulitis stage since it changes the environment in the infection, decreasing the risk of dissemination and tissue necrosis. In deep neck infections it is almost impossible to diagnose clinically or radiographically the formation of an abscess, therefore, waiting is not recommend [46]. On the contrary, those who advise waiting for the formation of an abscess, based on the fact that cellulitis can remit with antibiotic therapy and the elimination of the infection source avoiding an invasive procedure [16].

The incision is made under certain principles such as avoiding neurovascular structures, at the lowest possible point in the tension zone, following the facial relaxation lines and must be supported by healthy skin and subcutaneous tissue [46]. Intraorally, incisions are made at the point of maximum swelling or through the gingival sulcus [9]. The use of a surgical drain may be necessary, allowing the exit of fluids through the wound and facilitating the irrigation of the site [46].

\section{Follow-up}

Mild OI should be evaluated at 48 hours to assess the progress or resolution of the infection [10]. Severe OI in which ID and drain placement was performed require daily wound irrigation, as well as drain change every 72 hours. Between 48 and 72 hours postoperatively, trismus, pain, inflammation and neutrophil count should decrease [46].

If there is no favorable evolution of the patient within 48 postoperative hours, laboratory tests, imaging studies and rotation of antibiotic therapy should be updated until adequate evolution is observed. The patient can be discharged once there is remission of the infectious process [46].

\section{Conclusion}

Odontogenic infection is polymicrobial, being gramnegative rodsandgram-positivecoccithe most frequently found; complications derived from odontogenic infections can be lethal if not well controlled and the most important factor in the resolution of the infection is the elimination of the primary source along with antibiotic therapy. Is a frequently consulted pathology; therefore, the clinician should know the basics on the management in order to prevent it from progressing and putting the patient's life at risk. This work provides information about odontogenic infection that allows to asses its presentation and possible complications; as well as, guidelines for diagnosis and management.

\section{Declarations}

\section{Acknowledgements}

Not applicable.

\section{Funding}

No funding was received.

\section{Competing interests}

The authors declare they have no competing interests.

\section{References}

1. Monasterio RB, Henriquez SG (2018) Prevalence and characterization of Odontogenic Infections in the Public Assistance Emergency Hospital between the Months of July to September of the Year 2015: Prospective Study. 12.

2. Topazian RG, Goldberg MH, Hupp JR (2002) Oral and Maxillofacial Infections. ( $4^{\text {th }}$ edn), Philadelphia, London, New York, St. Louis, Sydney, Toronto: W.B. Saunders Company.

3. Gonçalves L, Lauriti L, Yamamoto MK, Luz JGC (2013) Characteristics and Management of Patients Requiring Hospitalization for Treatment of Odontogenic Infections. Journal of Craniofacial Surgery 24: e458-e462.

4. Ogle OE (2017) Odontogenic Infections. Dental Clinics of North America 61: 235-252. 
5. Rastenienè R, Pūrienè A, Aleksejūnienè J, Pečiulienè V, Zaleckas L (2015) Odontogenic Maxillofacial Infections: A Ten-Year Retrospective Analysis. Surgical Infections 16: 305-312.

6. DeAngelis AF, Barrowman RA, Harrod R, Nastri AL (2014) Review article: Maxillofacial emergencies: Oral pain and odontogenic infections: Oral Pain and Odontogenic Infections. Emerg Med Australas 26: 336-342.

7. Gordon NC, Connelly S (2003) Management of head and neck infections in the immunocompromised patient. Oral and Maxillofacial Surgery Clinics of North America 15: 103110.

8. Rich R, Fleisher T, Schwartz B, et al. (2008) Clincial immunology and practice.3rd ed. St. Louis: Mosby-Year Book Inc.

9. Troeltzsch M, Lohse N, Moser N, Kauffman P, Cordesmeyer $R$, et al. (2015) A review of pathogenesis, diagnosis, treatment options, and differential diagnosis of odontogenic infections: A rather mundane pathology? Quintessence International 46: 351-361.

10. Velasco MI, Soto NR (2012) Principios para el tratamiento de infecciones odontogénicas con distintos niveles de complejidad. Rev Chil Cir 64: 586-598.

11. Peters S, Wormuth W, Sonis T (1996) Risk Factors Affecting Hospital Length of Stay in Patients With Odontogenic Maxillofacial Infections. J Oral Maxillofac Surg 54: 13861391.

12. Park J, Lee JY, Hwang DS, Kim YD, Shin SH, et al. (2019) A retrospective analysis of risk factors of oromaxillofacial infection in patients presenting to a hospital emergency ward. Maxillofac Plast Reconstr Surg 41: 49.

13. Castellanos Suárez JL, Díaz Guzmán LM, Lee Gomez EA (2015) Medicina en Odontología: manejo dental de paceintes con enfermedades sistémicas. ( $3^{\text {rd }}$ edn), México DF, México: El Manual Moderno 186-216.

14. Berlanga-Acosta J (2010) Cellular and molecular insights into the wound healing mechanism in diabetes. Biotecnologíaaplicada 27: 255-261.

15. Haug RH (2003) The changing microbiology of maxillofacial infections. Oral and Maxillofacial Surgery Clinics of North America 15: 1-15.

16. Taub D, Yampolsky A, Diecidue R, Gold L (2017) Controversies in the Management of Oral and Maxillofacial Infections. Oral and Maxillofacial Surgery Clinics of North America 29: 465-473.

17. Brook I, Sandor G, Jeffcoat M, Samaranayake L, Vera Rojas $\mathrm{J}$ (2007) Clindamicina para el tratamiento de infecciones dentales. Revista ADM 64: 230-237.

18. Peters BM, Jabra-Rizk MA, O'May GA, Costerton JW, Shirtliff ME (2012) Polymicrobial Interactions: Impact on Pathogenesis and Human Disease. Clinical Microbiology Reviews 25: 193-213.

19. Loredo SBE, Romo MSA, Frías MÁN, Vargas LOS (2020) Principios fundamentales para el diagnóstico, manejo y tratamiento de las infecciones odontogénicas. Revisión de la literatura. Revista Odontológica Mexicana 24: 9-19.

20. Hupp JR, Ellis EI, Tucker MR (2019) Contemporary Oral and Maxillofacial Surgery. ( $7^{\text {th }}$ edn), Philadelphia, PA: Elsevier 318-363

21. Flynn T, Wiltz M, Adamo A, Levy M, McKitnick J, et al. (1999) Predicting lenght of hospital stay and penicilin failure in severe odontogenic infections. Int J Oral Maxillofac Surg 28: 48.
22. Seppänen L, Lauhio A, Lindqvist $C$, Suuronen $R$, Rautemaa $\mathrm{R}$ (2008) Analysis of systemic and local odontogenic infection complications requiring hospital care. Journal of Infection 57: 116-22.

23. Yılmaz S, Baş B, Özden B, Selçuk Ü, ÇengelKurnaz S (2015) Deep neck infection after thrid molar extraction. J Istanbul Univ Fac Dent 49: 41-45.

24. da Silva Junior AF, de Magalhaes Rocha GS, da Silva Neves de Araujo CF, Franco A, Silva RF (2017) Deep neck infection after third molar extraction: A case report. J Dent Res Dent Clin Dent Prospects 11: 166-169.

25. Bali R, Sharma P, Gaba S, Kaur A, Ghanghas P (2015) A review of complications of odontogenic infections. Natl $\mathrm{J}$ MaxillofacSurg 6: 136-143.

26. Mardini S, Gohel A (2018) Imaging of Odontogenic Infections. Radiologic Clinics of North America 56: 31-44.

27. Sklavos A, Beteramia D, Delpachitra SN, Kumar R (2019) The panoramic dental radiograph for emergency physicians. Emerg Med J 36: 565-571.

28. Weyh AM, Dolan JM, Busby EM, Smith SE, Parsons $M E$, et al. (2021) Validated image ordering guidelines for odontogenic infections. International J Oral Maxillofac Surg 50: $627-634$.

29. Christensen BJ, Park EP, Suau S, Beran D, King BJ (2019) Evidence-Based Clinical Criteria for Computed Tomography Imaging in Odontogenic Infections. J Oral Maxillofac Surg 77: 299-306.

30. Miloro M, Ghali GE, Larsen PE, Waite PD (2011) Peterson's Principles of Oral and Maxillofacial Surgery. ( $3^{\text {rd }}$ edn), Shelton, Connecticut: People's Medical Publishing HouseUSA, 841-859.

31. Moncada R, Warpeha R, Pickleman J, Spak M, Cardoso $M$, et al. (1978) Mediastinitis from odontogenic and deep cervical infection. Anatomic pathways of propagation. Chest 73: 497-500.

32. Miller CR, Von Crowns K, Willoughby V (2018) Fatal Ludwig's Angina: Cases of Lethal Spread of Odontogenic Infection. Academic Forensic Pathology 8: 150-169.

33. Chatterji P, Goyal I (2018) Temporoparietal and Infratemporal fossa abscess as a complication of dental extraction-a rare and potentially lethal condition. Asian $\mathrm{J}$ Med Sci 9: 57-60.

34. Cariati P, Cabello-Serrano A, Monsalve-Iglesias F, Roman-Ramos M, Garcia-Medina B (2016) Meningitis and subdural empyema as complication of pterygomandibular space abscess upon tooth extraction. J Clin Exp Dent 8: e469-e472.

35. González-Navarro B, Arranz-Obispo C, Albuquerque R, Jané-Salas E, López-López J (2017) Osteomyelitis of the jaw (with pathological fracture) following extraction of an impacted wisdom tooth. A case report. J Stomatol Oral and Maxillofac Surg 118: 306-309.

36. Maraki S, Papadakis IS, Chronakis E, Panagopoulos D, Vakis A (2016) Aggregatibacteraphrophilus brain abscess secondary to primary tooth extraction: Case report and literature review. Journal of Microbiology, Immunology and Infection 49: 119-122.

37. Moazzam AA, Rajagopal SM, Sedghizadeh PP, Zada G, Habibian M (2015) Intracranial bacterial infections of oral origin. J Clin Neurosci 22: 800-806.

38. Aggarwal K, Rastogi S, Joshi A, Kumar A, Chaurasia A, et al. (2017) Cavernous sinus thrombosis following dental 
extraction: A rare case report and forgotten entity. J Korean Assoc Oral Maxillofac Surg 43: 351.

39. Carter L, Lowis E (2007) Death from overwhelming odontogenic sepsis: A case report. Br Dent J 203: 241-242.

40. Jiménez Y, Bagán JV, Murillo J, Poveda R (2004) Infecciones odontogénicas.Complicaciones. Manifestaciones sistémicas. Med Oral Patol Oral Cir Bucal 9: S139-S147.

41. Bullock J, Fleishman J (1985) The spread of odontogenic infections to the orbit: Diagnosis and management. J Ora Maxillofac Surg 43: 749-755.

42. Youseff O, Stefanyszyn M, Bilky J (2008) Odontogenic orbital cellulitis. Ophtal Plast Reconstr Surg 24: 29-35.

43. Dolezalova H, Zemek J, Tuček L (2015) Deep Neck Infections of Odontogenic Origin and Their Clinical Significance. A Retrospective Study from Hradec Králové, Czech Republic. Acta Medica 58: 86-91.
44. Zeitoun I, Dhanarajani P (1995) Cervical cellulitis and mediastinitis caused by odontogenic infections: Report of two cases and review of literature. J Oral Maxillofac Surg 53: 203-208.

45. Goldberg MH (2003) Diagnosis and treatment of cervicofacial actinomycosis. Oral and Maxillofacial Surgery Clinics of North America 15: 51-58.

46. Flynn RT (2000) Surgical management of orofacial infections. Atlas of the Oral and Maxillofacial Surgery Clinics of North America 8: 77-100.

47. Greenberg S, Huang J, Chang R, Ananda S (2007) Surgical management of Ludwig's angina. ANZ J Surg 77: 540-543.

48. Boscolo-Rizzo P, Da Mosto M (2009) Submandibular space infection: a potentially lethal infection. Int Infect Dis 13: $227-233$

49. Flavell E, Stacey M, Hall J (2009) The clinial management of airway obstruction. Curr Anaesth Crit Care 20: 102-112. 